\title{
An Applicable Technical Analysis Based on Accomplishment of Vehicle Troop Monitoring System
}

\author{
An Li \\ College of Sciene, Air Force Engineering Universty, Xi'an, \\ Shaanxi, China, 710038 Xi'an Research Institute of \\ Hi-Tech,Sian Shaanxi,China,710025 56337922@qq.com

\section{YeXuemei} \\ Xi'an Research Institute of Hi-Tech, Sian Shaanxi, China, \\ 710025, 56337922@qq.com
}

\begin{abstract}
Nowadays motorcades are often used in entertainment and work in our daily life. Accordingly, it has become our major concern about ensuring the security of a motorcade, improving coordination of all the vehicles in the course of driving and increasing the efficiency of accomplishing various tasks. This paper proposes an idea about devising a motorcade monitoring system, designs a functional structure of the system, constructs a motorcade structure model according to its features and sets the distance between vehicles at different speed as well. ZigBee is selected to apply for monitoring a motorcade by applicable technical analysis. Besides, the effects of mobility of vehicle nodes upon application of ZigBee are analyzed in this paper.
\end{abstract}

Keywords-motorcade, monitoring system, ZigBee

\section{I.INTRODUCTION}

Nowadays, motorcades are often seen in our daily life especially in "self-driving travelling" appealing to many owners of private cars. More and more owners take part in group self-driving travelling and form motorcades voluntarily while some units set up their own motorcades. It's really a grand vision of dozens of vehicles extending several kilometers. In these cases, however, lagging behind or interlinking rear-end collisions are most likely happened. Interphones are usually used to direct ways, inform road condition and emergencies as well as monitor the advancing motorcade. Yet due to the poor signal in some remote areas, a motorcade sometimes fails to reach its destination. During the moving process of a motorcade, probability of vehicle failure certainly would be decreased on condition that divers could anticipate and immediately settle the malfunction or hidden trouble in the vehicle by watching the changes of temperature, humidity, speed and acceleration in the key parts, thereby the viability of a motorcade would also be enhanced. In addition, some relative studies have shown that most traffic accidents would be avoided if drivers could be aware of the accident just one second in advance and take effective measures. That means traffic accidents would be probably avoided through a diver's perception of the distance between his/her own vehicle and others, and the information intercommunicating among all the vehicles. But presently, that can't be brought into actuality due to lack of

\author{
Zhang YuTong \\ College of Sciene, Air Force Engineering Universty, Xi’an, \\ Shaanxi, China, 710038, \\ 56337922@qq.com
}

TianJun

Postdoctoral Working Station of Nanjing General Hospital of Nanjing Military Command, Nanjing, China, 56337922@qq.com

intercommunication devices and supervising means in moving process of a motorcade. To solve the above problems, this paper proposed a Motorcade Monitoring System to ensure its safe driving and high efficiency of accomplishing various tasks; meanwhile analyzed the technologies applied to performing the monitoring functions.

\section{II.THE GENERAL FUNCTIONS OF A MOTORCADE MONITORING SYSTEM}

The specific methods of implementing a monitoring system are provided in the following:

A specific functional structure of a monitoring system is illustrated in Figure 2.1:

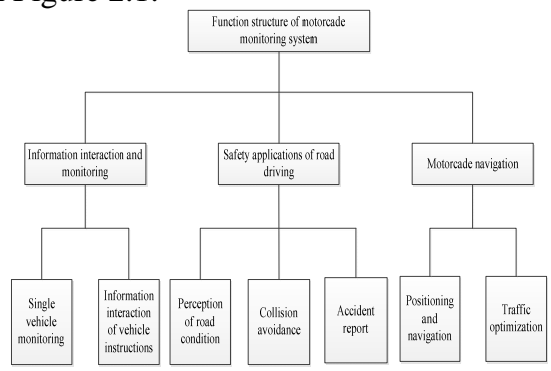

Figure 2.1: Function Structure of a Motorcade Monitoring System

As is shown in Figure 2.1, a motorcade monitoring system consists of three major modules: information intercommunicating and monitoring, applications of safe road driving and motorcade navigation. Each module is composed of different functional modules that are explained one by one in the following:

(1) Monitoring single vehicle

The condition of a single vehicle is collected by sensor terminals including temperature and humidity sensor, speed/acceleration sensor, smog sensor, pressure sensor, etc. by which to achieve fault alarm and location. In this way the whole motorcade can keep running safely and smoothly.

(2)Intercommunication of vehicles' command information

It refers to the function that the vehicles in a motorcade send instructions to the leading vehicle by means of broadcast or unicast and intercommunicate command 
information among one another.

(3)Perception of road condition

Auto-perception of road condition is conducted by Vehicular ad-hoc network technology, which will enhance the viability of a motorcade.

(4)Collision avoidance

In the moving process, vehicles collect and judge automatically the information about the surrounding vehicles and barriers, and send early warning to avoid possible collisions.

(5)Accident alarm

Once a traffic accident occurs, peripheral information collection equipment broadcasts it to all the vehicles automatically and immediately to arrest its course.

(6) Location and navigation

Location and navigation of a motorcade are accomplished by means of satellite positioning technology and visualization electronic map.

(7) Route optimization

Load-on electronic map is used to provide bases for decision of a motorcade's advancing route.

\section{III.ESTABLISHMENT OF A MOTORCADE STRUCTURE MODEL AND DETERMINATION OF VEHICLE-VEHICLE DISTANCE}

\section{A.A Motorcade Structure Model}

There are two types of a Motorcade Model: Motorcade Dynamic Model and Motorcade Structure Model. In the studies of motorcade intelligent control, devising a vehicle controller is based on setting up a motorcade dynamic model. Presently, longitudinal dynamic model concerning a motorcade is generally divided into two types: dynamic model employing liner control rule and mingling dynamic model with limitation. In the researches on organization of motorcade communication network, specific motorcade dynamic models are needed to set up aiming at the organizational characteristics of different fleet types. Therefore, this paper focuses on the organization of cordless communication network in a motorcade to perform information intercommunication functions of all the vehicles in it.

The Established Motorcade Structure Model is shown in Figure 3.1:

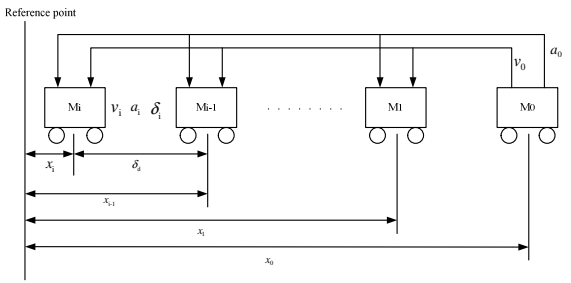

Figure 3.1: The Established Motorcade Structure Model

In this model, $x_{0}, x_{1}, x_{i-1}, x_{i}$ are the reference positions of the vehicles in a motorcade, $\delta_{d}$ is the expected vehicle-vehicle distance, $\delta_{i}$ is defined as the error between Vehicle $i$ and Vehicle $i-1$, an equation is shown here:

$$
\delta_{i}=x_{i-1}-x_{i}-\delta_{d}
$$

In order to control and maintain the overall stability of a motorcade, the following information must be acquired in time by each vehicle in it by sensors or through the communication network among them: the acceleration and speed of this vehicle, the distance between this vehicle and the preceding one, the acceleration and speed of the preceding vehicle and the leading vehicle. Among all the information, the acceleration and speed of the leading vehicle can only be acquired through vehicle communication network while other information can be acquired through by sensors. The acceleration and speed of the preceding vehicle can be acquired by both methods. Here, taking the information intercommunication of the acceleration and speed of the leading vehicle as an example, a motorcade structure model with intercommunication function of the vehicles is shown in Figure 3.1.

The motorcade structure model shown in Figure 3.1 indicates that the stable and smooth cordless communication network established by the vehicles in a motorcade will make Vehicle i acquire the information of the acceleration and speed of Vehicle i-1and the leading vehicle in time and then process and use the information. Besides, this cordless communication network will also satisfy the needs of intercommunicating other information among the vehicles in a motorcade, such as command information, fault alarm, etc.

\section{B. Determination of Vehicle-vehicle Distance}

The analysis of highway traffic accidents shows that over $65 \%$ of the accidents resulted from pileup and $80 \%$ of them were due to slow reaction of the drivers. As a result, to prevent pileup among the vehicles in a motorcade is a matter of prime importance in maintaining the whole motorcade's safety and stability. Therefore, it is of significance to provide a criterion by determining the vehicle-vehicle distance.

There are three common safe vehicle distance models: the first one is a fixed safe distance model, in which fixed distance $\mathrm{C}$ conducts as a critical value of safe distance; the second one is a safe distance model based on braking process, in which a safe vehicle-vehicle distance $S=S_{1}+S_{2}+S_{3}$ is worked out by means of a vehicle's braking feature combined with the driver's reaction time and the vehicle's present speed and braking process, in the equation, ${ }^{S_{1}}$ refers to a vehicle's running distance within the time of the driver's reaction and its braking process, $S_{2}$ refers to a vehicle's running distance within the time of braking acceleration lengthening, $S_{3}$ refers to a vehicle's running distance within the time of sustained braking; the third one is a safe distance model based on the present vehicle-vehicle distance, in which a safe vehicle-vehicle distance can be obtained by the result analyzed a huge mass of statistical data from actual highway travel that under actual transportation condition that the vehicles run in line at 
relative slow speed, $D_{S}$ (the distance between the front target vehicle and this vehicle) has linear relation with $\mathrm{V}$ (this vehicle's present speed), showing as the equation 2:

$$
D_{S}=V T_{0}+d
$$

In the above equation, $T_{0}$ is the headway, which represents the ratio of the vehicle-vehicle distance and their speed, the unit is $s ; V$ is the vehicle's present speed, the unit is $m / s$, $d$ is revised value, the unit is $m$, values ranging from $-5 \sim 5$.

According to the above three motorcade structure models, a safe distance model based on the headway is selected in this paper to determine the safe vehicle-vehicle distance. In the meantime, $T_{0}$ (the headway) is determined in accordance with the rules of safe distance at various speeds in Road Traffic Safety Law of the People's Republic of China.

In this paper, parameter $T_{0}$ is set to be $3.5 \mathrm{~S}$ in accordance with the rule that the safe vehicle-vehicle distance should reach $100 \mathrm{~m}$ at the speed of $100 \mathrm{~km} / \mathrm{h}$.

For the sake of safety, the speed of a whole motorcade usually maintains at about $15 \sim 80 \mathrm{~km} / \mathrm{h}$ depending on the road conditions. Consequently, safe vehicle-vehicle distances for all the vehicles in a motorcade are shown in Table 3.1 according to the different driving speeds and the determination of safe distance within a motorcade as well as its specific driving speed.

Table 3.1: Vehicle-vehicle Distances for All the Vehicles in a Motorcade

\begin{tabular}{|c|c|c|}
\hline \multicolumn{2}{|c|}{$\begin{array}{l}\text { Motorcade's } \\
\text { Speed }\end{array}$} & \multirow{2}{*}{\begin{tabular}{l}
\multicolumn{1}{c}{ Safe } \\
Vehicle-vehicle \\
Distance $(\mathrm{m})$
\end{tabular}} \\
\hline $\mathrm{km} / \mathrm{h}$ & $\mathrm{m} / \mathrm{s}$ & \\
\hline 15 & 4.17 & 10 \\
\hline 30 & 8.33 & 30 \\
\hline 45 & 12.5 & 45 \\
\hline 60 & 16.67 & 60 \\
\hline 80 & 22.22 & 80 \\
\hline
\end{tabular}

\section{THE ANALYSES OF THE APPLIED TECHNOLOGIES}

\section{A.Application Requirements of a Motorcade Monitoring} System

Proper communication technologies should be selected to construct a systemic cordless communication network suiting the features of a motorcade's moving process: all the vehicles should keep in a fixed order, one vehicle should follow the preceding one and maintain certain distance between them, safe vehicle-vehicle distances for all the vehicles in a motorcade range from $10 \sim 100 \mathrm{~m}$, etc. Moreover, selection of specific communication technologies should consider both the requirements of the monitoring system and the features of cordless communication technologies.
On account of the definition of a motorcade monitoring system and its functions, the basic application requirements of the motorcade monitoring system are: numerous nodes, enough communication bandwidth and cordless communication distance, communication link, reliable safety and good anti-interference capability, low cost, small size as well as convenient installation.

\section{B. Applied Technologies}

At present, mainstream technologies in short-range cordless communication mainly include Bluetooth (BT), Wireless Fidelity (Wi-Fi), Infrared Data Association (IrDA), Ultra Wideband (UWB), Near Field Communication (NFC) and ZigBee, etc. Different technologies in short-range cordless communication have their own technical properties.

1. BT is incapable of constructing a proper motorcade's network due to its maximum 8 network nodes, though it has advantage of low energy consumption, low data transfer rate and low cost as well as its cordless transmission distance can be lengthened by power amplifiers.

2. UWB sends data by the action of

baseband pulse mode on antennas, which is mainly used in image system of short range and high resolution, and the radar that is capable to penetrate wall, ground and body as well as some applications with high data transfer rate.

3. Wi-Fi meets the demands of a motorcade monitoring system in node capacity and cordless transmission distance, but it is hard to be configured in large scale in a motorcade due to its high energy consumption, expensive price and big size.

4. ZigBee is one of the short-range cordless communication technologies. Generally speaking, short-range cordless communication refers to the two communicating parties communicate by means of cordless communication with the limited communication distance of dozens of metres, whose features and advantages are low cost, low power consumption and peer-to-peer communication. ZigBee meets the demands of a motorcade monitoring system in node capacity and cordless transmission distance combined with very low energy consumption, low cost and easy installation for its simple configuration. The single defect of ZigBee is that its data transfer rate is $250 \mathrm{Kbps}$, which is enough for a motorcade monitoring system.

Table 4.1 shows the comparison of ZigBee, BT, Wi-Fi and UWB.

Table 4.1: Comparisons of Several Short-range Cordless Communication Technologies

\begin{tabular}{|l|l|l|l|l|}
\hline & $\mathrm{BT}$ & $\mathrm{UWB}$ & $\mathrm{Wi}-\mathrm{Fi}$ & Zigbee \\
\hline Standard & 802.15 .4 & $802.15 .3 \mathrm{a}$ & 802.11 & 802.15 .4 \\
\hline $\begin{array}{l}\text { Frequency } \\
\text { band }\end{array}$ & $2.4 \mathrm{GHZ}$ & $\begin{array}{l}3.1-10.6 \\
\mathrm{GHZ}\end{array}$ & $\begin{array}{l}2.4 \mathrm{GHZ} ; \\
5 \mathrm{GHZ}\end{array}$ & $\begin{array}{l}868 / 915 \\
\mathrm{MHZ} \\
2.4 \mathrm{GHZ}\end{array}$ \\
\hline $\begin{array}{l}\text { Maximum } \\
\text { Transmission } \\
\text { Rate }\end{array}$ & $1 \mathrm{Mbps}$ & $110 \mathrm{Mbps}$ & $54 \mathrm{Mbps}$ & $250 \mathrm{Kbps}$ \\
\hline $\begin{array}{l}\text { Maximum } \\
\text { Network Nodes }\end{array}$ & 8 & 8 & 2007 & 65336 \\
\hline $\begin{array}{l}\text { Communication } \\
\text { Range }\end{array}$ & $10 \mathrm{~m}$ & $10 \mathrm{~m}$ & $\begin{array}{l}10 \sim \\
100 \mathrm{~m}\end{array}$ & $10 \sim 100 \mathrm{~m}$ \\
\hline
\end{tabular}




\begin{tabular}{|c|c|c|c|c|c|}
\hline & $\begin{array}{l}\mathrm{R} \\
\mathrm{X}\end{array}$ & 84.6 & 750.09 & 709.5 & 81 \\
\hline $\begin{array}{l}\quad \text { Proto } \\
\text { col Power } \\
\text { Dissipation } \\
\text { of } \\
\text { Mainstream } \\
\text { Chip (mW) }\end{array}$ & $\begin{array}{l}\mathrm{T} \\
\mathrm{X}\end{array}$ & 102.6 & 750.09 & 722.7 & 74.1 \\
\hline
\end{tabular}

C.The Impact Analysis of High-speed Moving of Vehicle Nodes on ZigBee Application

In the application of ZigBee to a motorcade monitoring system, prompt response time, swift data transmission and processing of communication nodes are required to guarantee the reception rate of data transmission as a result of the high-speed moving of vehicle nodes in a motorcade. Suppose there are two moving vehicles conducting communication in a motorcade shown in Figure 4.1.

As shown in Figure 4.1, suppose $\mathrm{T}$ represents the permissible response time of cordless communication between vehicle nodes in ZigBee network, an equation can be obtained as:

$$
T=\frac{2 L}{V_{T}}-\frac{D}{V_{D}}-\delta
$$

In the equation $3, \mathrm{~L}$ is the network distance with the unit of $\mathrm{m}$; $V_{T}$ is the relative moving speed of Vehicle A and B with the unit of $\mathrm{m} / \mathrm{s}$; $\mathrm{D}$ is the data volume to transmit with the unit of kbit; $V_{D}$ is the data transmission rate with the unit of kbps; $\delta_{\text {is the transmission time of electromagnetic }}$ wave signals.

The transmission time of electromagnetic wave signals is omitted owing to the high transmission speed of electromagnetic waves and equation 3can be simplified as:

$$
T=\frac{2 L}{V_{T}}-\frac{D}{V_{D}}
$$

The minimum response time in ZigBee communication network is $60 \mathrm{~ms}$, permissible response time $\mathrm{T}$ must be longer than $60 \mathrm{~ms}$ in order to complete communication between the moving vehicles. Suppose

$$
\begin{aligned}
& L=100 \mathrm{~m}, V_{T}=23 \mathrm{~m} / \mathrm{s} \approx 80 \mathrm{~km} / \mathrm{h}, D=128 \mathrm{kbit}, \\
& V_{D}=250 \mathrm{kbps} \text {,then } \\
& t=\frac{2 \times 100}{23}-\frac{128}{250}=8.184 \mathrm{~s}
\end{aligned}
$$

In the equation 5, permissible response time $\mathrm{T}$ is $8.184 \mathrm{~s}$.

The time delay of ZigBee network is quite short, for example, searching delay of typical equipment is $30 \mathrm{~ms}$, activating hibernation delay is $15 \mathrm{~ms}$, time delay of equipment accessing to network is $15 \mathrm{~ms}$. That is to say, it usually takes ZigBee nodes about $60 \mathrm{~ms}$ to accomplish network organization and data transmission. 8.184s, obtained in equation 4.3 , is much longer than $60 \mathrm{~ms}$, which is the minimum response time in network organization of ZigBee. In addition, relative speed of moving vehicles in a motorcade is not high and in most cases, the vehicles in a motorcade will keep going in a relatively static movement, in which there will be no relative speed at $80 \mathrm{~km} / \mathrm{h}$, suggested in the equation 4.3. Thereby a conclusion can be drawn that ZigBee network can guarantee the information transmission among the vehicles in a motorcade when vehicle nodes move at high speed.

\section{V.CONCLUSION}

This paper has explained the functions of a motorcade monitoring system, established a motorcade structure model according to the motorcade's driving features, determined the relationship between vehicle-vehicle distance and the motorcade's moving speed on the basis of this model and analyzed the application of ZigBee in the monitoring system. The final conclusion is that ZigBee is feasible to accomplish monitoring functions either in a self-driving motorcade or other motorcade types, which lays a firm foundation for the future full realization of a motorcade monitoring system.

\section{REFERENCE}

[1]J.S. L, Yu-Wei S, Chung-Chou S, et al. A Comparative Study of Wireless Protocols: Bluetooth, UWB, ZigBee, and Wi-Fi[C]//Proceedings of the 33rd Annual Conference of the IEEE Industrial Electronics Society, 2007.

[2]NAVARRO A, SILLER M. A node localization scheme for zigbee-based sensor networks[C]//Proceedings of the 2009 IEEE International Conference on Systems, Man, and Cybernetics, San Antonio, TX, USA, 2009.

[3]Pontin, Jason. 10 Emerging Technologies[J]. Technology Review, 2012, 115(3): 12-13.

[4]Liu W, Lu K, Wang J, Xing G, Huang L, et al. Performance Analysis of Wireless Sensor Networks With Mobile Sinks[J]. Vehicular Technology, 2012, 61(6):2777-2788.

[5]Nieuwenhuijze, M. R. I, van KT, Oncu S, Bonsen B, Nijmeijer H, et al. Cooperative Driving With a Heavy-Duty Truck in Mixed Traffic: Experimental Results[J]. Intelligent Transportation Systems, 2012, 13(3): 1026-1032. 